\title{
GENETIC POLYMORPHISM OF THE SECOND COMPONENT OF HUMAN COMPLEMENT (C2) IN JAPANESE
}

\author{
Katsushi Tokunaga, Keiichi Omoto, ${ }^{1}$ Chieko Arakı, ${ }^{2}$ and Takeo Jusı ${ }^{3}$ \\ ${ }^{1}$ Department of Anthropology, Faculty of Science, The University of Tokyo, \\ Tokyo 113, Japan \\ ${ }^{2}$ Department of Research, Japanese Red Cross Central Blood Center, \\ Tokyo 150, Japan \\ ${ }^{3}$ Blood Transfusion Service, Tokyo University Hospital, \\ Tokyo 113, Japan
}

\begin{abstract}
Summary Polymorphism of the second component of human complement (C2) was investigated in a total of 292 sera from unrelated adult Japanese using a slab polyacrylamide gel isoelectric focusing followed by a specific hemolytic assay. Besides the common phenotype (C), two relatively infrequent double-banded phenotypes $(\mathrm{AC}$ and $\mathrm{BC}$ ) were $\mathrm{ob}-$ served, which were considered to be heterozygotes. The estimated frequencies for the common allele, $C 2^{C}$, and the variant alleles, $C 2^{A}$ and $C 2^{B}$, were $0.937,0.046$, and 0.017 , respectively. 229 samples were further typed for HLA-A, HLA-B, and HLA-C, and the result indicated the presence of significant association of $C 2^{A}$ with $H L A-B 15$. This finding suggests that in Japanese there is an allelic combination showing linkage disequilibrium between $\mathrm{C} 2$ and HLA loci which is different from those in Caucasians.
\end{abstract}

\section{INTRODUCTION}

The second component of human complement (C2) is one of the components of the classical complement pathway with a single polypeptide chain of M.W. 102,000 (Polley and Müller-Eberhard, 1968; Kerr and Porter, 1978).

Hereditary deficiency of $\mathrm{C} 2$ has been reported to be relatively common in Caucasian populations, the deficient gene frequency being approximately $1 \%$ (Agnello, 1978), while it is not thus far reported in Japanese. Close linkage between the $\mathrm{C} 2$ locus and the MHC region was observed in the families with homozygous C2 deficiency (Fu et al., 1974; Day et al., 1975).

Genetic polymorphism of human $\mathrm{C} 2$ and its linkage with HLA was recently discovered in Caucasian populations using isoelectric focusing (Hobart and Lachmann, 1976; Alper, 1976; Meo et al., 1977). The polymorphism was shown to 
be controlled by codominant alleles at a single locus situated very close to HLA-D locus (Raum et al., 1979; Dewald and Rittner, 1979). As to Asian populations, a single study on a very small sample of "Orientals" in USA has been published, though there was no detailed information concerning the racial status of the sample (Alper, 1976).

In this report, we present the result of the population study of $\mathrm{C} 2$ polymorphism in Japanese using a slab polyacrylamide gel isoelectric focusing followed by the specific hemolytic assay. Moreover, the HLA (A, B and C) typing were also carried out in order to examine the presence of linkage disequilibrium between $C 2$ and HLA loci.

\section{MATERIALS AND METHODS}

A total of 292 sera or plasmas obtained from unrelated healthy adults living in Tokyo were used for population study of C2. Among these, 229 blood samples were also typed for the HLA (A, B and C) specificities. Samples for C2 typing had been stored at $-40^{\circ} \mathrm{C}$ up to several weeks until used.

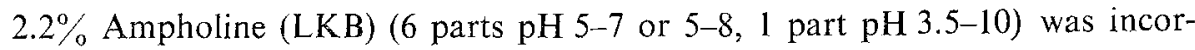
porated into $5.0 \%$ polyacrylamide gel (thickness $1 \mathrm{~mm}$ ) with $0.2 \mathrm{M}$ taurine (Alper, 1976). The gel was photopolymerized with riboflavin. After prefocusing at $600 \mathrm{~V}$ constant voltage for $1 \mathrm{~h}$ (electrode distance $11 \mathrm{~cm}$ ), ca. $20 \mu 1$ of undiluted samples were applied with pieces of filter paper at the anodal side of the gel, and the voltage was raised to $800 \mathrm{~V}$. After $1 \mathrm{~h}$, filter paper pieces were removed and the voltage was raised and kept constant at $1,000 \mathrm{~V}$ for $2.5-3.5 \mathrm{~h}$.

The gel after focusing was washed in $5 \times 10^{-5} \mathrm{M} \mathrm{I}_{2} / \mathrm{PBS}(\mathrm{pH} \mathrm{6.0)}$ ) for $10 \mathrm{~min}$ at $37^{\circ} \mathrm{C}$ in order to increase $\mathrm{C} 2$ activity (Polley, 1971; Olaisen et al., 1978). The gel was then layered with $0.8 \%$ agarose gel (thickness $1 \mathrm{~mm}$ ) in isotonic veronal buffered saline at pH 7.4 containing $0.1 \%$ gelatin, $1 \mathrm{~mm} \mathrm{MgCl}$ and $0.15 \mathrm{mM} \mathrm{CaCl}_{2}\left(\mathrm{GVB}^{2+}\right)$, $0.8 \%$ sheep erythrocytes sensitized with rabbit antibody (EA), and about $0.8 \%$ normal human serum instead of C2 deficient serum (Olaisen et al., 1978). Hemolytic bands appeared after $2-4 \mathrm{~h}$ incubation at $37^{\circ} \mathrm{C}$.

In an alternative method (Nishioka et al., 1966), 0.8\% agarose gel (thickness $1 \mathrm{~mm}$ ) in $\mathrm{GVB}^{2+}$ containing $0.7 \%$ EACl4 intermediate cells was overlayed on the polyacrylamide gel. After $30 \mathrm{~min}$ of incubation at $37^{\circ} \mathrm{C}, \mathrm{C} 2$ bands were developed by further overlaying $0.5 \%$ agarose gel containing $10 \%$ fresh guinea pig serum with $0.01 \mathrm{M}$ EDTA in veronal buffered saline. The EAC14 intermediate cells were obtained by sensitization of sheep erythrocytes with rabbit antibody in $0.01 \mathrm{M}$ EDTA contained gelatin veronal buffered saline, washing out of EDTA with $0.15 \mathrm{mM} \mathrm{CaCl} 2$ contained gelatin veronal buffered saline (GVB-Ca $\left.{ }^{2+}\right)$, and mixing of 20 parts of EA $\left(2 \times 10^{9} \mathrm{cell} / \mathrm{ml}\right)$ in $\mathrm{GVB}-\mathrm{Ca}^{2+}$ and 1 part of fresh guinea pig serum for $7.5 \mathrm{~min}$ at $0^{\circ} \mathrm{C}$.

HLA (A, B and C) typing were carried out using peripheral blood lymphocytes by means of the standard microcytotoxicity technique. 
Allele and haplotype frequencies, coefficients of linkage disequilibrium (D value), and its corresponding standard errors were estimated from the population data using the formulae presented by Mittal et al. (1972).

\section{RESULTS}

By both detection methods mentioned above, essentially the same lytic pattern for $\mathrm{C} 2$ was obtained (Fig. 1). Therefore, the hemolytic assay using normal human serum (Alper-Olaisen's method) which is simpler than that of Nishioka and others was used routinely in the present study. The common phenotype (C2 C) consisted of three prominent bands and a few additional bands. Two kinds of relatively infrequent variant phenotypes were found. They showed double-banded patterns, one with the variant $\mathrm{C} 2$ component at the acidic side, and the other with that at the basic side of the common $\mathrm{C} 2$ band. They are tentatively called type $\mathrm{C} 2 \mathrm{AC}$

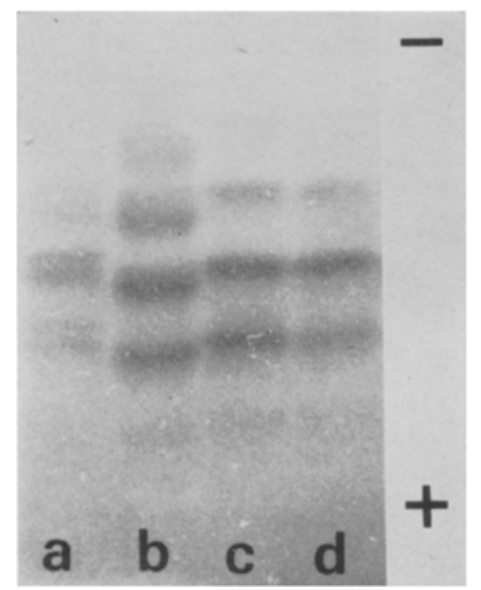

Fig. 1. Lytic patterns of $\mathrm{C} 2$ phenotypes obtained by isoelectric focusing and hemolytic assay. a, type $\mathrm{C} 2 \mathrm{BC} ; \mathrm{b}$, type $\mathrm{C} 2 \mathrm{AC}$; $\mathrm{c}$ and $\mathrm{d}$, type $\mathrm{C} 2 \mathrm{C}$.

Table 1. Distribution of phenotypes and allele frequencies of $\mathrm{C} 2$.

\begin{tabular}{ccccccccc}
\hline \multirow{2}{*}{ Total } & \multicolumn{7}{c}{ Phenotype } \\
\cline { 3 - 7 } & & \multicolumn{1}{c}{ C } & AC & BC & A & AB & B \\
\hline \multirow{2}{*}{292} & Obs. No. & 255 & 27 & 10 & 0 & 0 & 0 \\
& $\%$ & 87.3 & 9.2 & 3.4 & 0 & 0 & 0 \\
& Exp. No. & 256.17 & 25.29 & 9.37 & 0.62 & 0.46 & 0.09 \\
\hline
\end{tabular}

$\chi^{2}=1.335,3$ d.f., $0.70<\mathrm{p}<0.80$

Allele frequencies: $C 2^{C} 0.937 \pm 0.010, \quad C 2 A 0.046 \pm 0.009, \quad C 2^{B} 0.017 \pm 0.005$ 
Table 2. HLA-A,B,C, and C2 aliele frequencies estimated from 229 Japanese samples.

\begin{tabular}{llllll}
\hline Allele & Frequency & Allele & Frequency & Allele & Frequency \\
\hline$A 1$ & 0.0044 & $B w 44(12)$ & 0.0539 & $B w 46$ & 0.0154 \\
$A 2$ & 0.2553 & $B 13$ & 0.0198 & $B w 48$ & 0.0154 \\
$A w 24(9)$ & 0.3525 & $B 15$ & 0.1184 & $C w 1$ & 0.1184 \\
$A 26(10)$ & 0.1826 & $B w 39(16)$ & 0.0492 & $C w 2$ & 0.0088 \\
$A 11$ & 0.0867 & $B 17$ & 0.0044 & $C w 3$ & 0.3133 \\
$A w 31$ & 0.0820 & $B w 22$ & 0.0220 & $C w 4$ & 0.0378 \\
$A w 33$ & 0.0539 & $B w 54$ & 0.0655 & & \\
$B 5$ & 0.2322 & $B 27$ & 0.0022 & $C 2^{C}$ & 0.930 \\
$B w 51$ & 0.1012 & $B w 35$ & 0.1061 & $C 2^{A}$ & 0.050 \\
$B w 52$ & 0.1134 & $B 37$ & 0.0044 & $C 2^{B}$ & 0.020 \\
$B 7$ & 0.0492 & $B 40$ & 0.1907 & & \\
\hline
\end{tabular}

Table 3. HLA phenotypes of $\mathrm{C} 2 \mathrm{AC}$ and $\mathrm{C} 2 \mathrm{BC}$ individuals.

\begin{tabular}{|c|c|c|c|c|c|c|c|}
\hline Individual & C2 phenotype & & & A phen & & & \\
\hline 1 Y.A. & $\mathrm{AC}$ & Aw24 & Aw33 & $\mathrm{B} 40$ & Bw35 & Cw1 & \\
\hline 2 M.N. & $\mathrm{AC}$ & A26 & Aw33 & $\mathrm{B} 15$ & $\mathrm{~B} 40$ & $\mathrm{Cw} 3$ & \\
\hline 3 S.H. & $\mathrm{AC}$ & Aw24 & A26 & Bw35 & $\mathrm{B} 40$ & Cw3 & \\
\hline 4 C.T. & $\mathrm{AC}$ & Aw24 & A11 & Bw51 & Bw35 & Cw3 & \\
\hline 5 S.U. & $\mathrm{AC}$ & Aw24 & A26 & $\mathrm{B} 15$ & Bw54 & Cwl & \\
\hline 6 K.T. & $\mathrm{AC}$ & Aw24 & Aw31 & B7 & $\mathrm{B} 15$ & & \\
\hline 7 M.K. & $\mathrm{AC}$ & Aw24 & A26 & B15 & Bw35 & & \\
\hline 8 N.S. & $\mathrm{AC}$ & A.26 & & Bw35 & B40 & Cw3 & \\
\hline 9 T.I. & $\mathrm{AC}$ & Aw24 & & Bw52 & B15 & Cw1 & \\
\hline 10 T.N. & $\mathrm{AC}$ & $\mathrm{A} 2$ & Aw24 & Bw52 & B15 & Cw3 & \\
\hline $11 \mathrm{~S} . \mathrm{Y}$. & $\mathrm{AC}$ & Aw24 & A26 & B15 & Bw54 & Cw1 & Cw3 \\
\hline 12 G.S. & $\mathrm{AC}$ & Al1 & Aw31 & Bw39 & Bw54 & Cw1 & \\
\hline 13 K.S. & $\mathrm{AC}$ & Aw24 & A26 & Bw51 & $\mathrm{B} 15$ & Cw3 & \\
\hline 14 M.A. & $\mathrm{AC}$ & A26 & Aw31 & B15 & B40 & Cw3 & \\
\hline 15 M.H. & $\mathrm{AC}$ & $\mathrm{A} 2$ & A26 & B15 & Bw35 & Cw3 & \\
\hline 16 K.K. & $\mathrm{AC}$ & A26 & & Bw52 & $\mathrm{B} 15$ & Cw3 & \\
\hline 17 K.A. & $\mathrm{AC}$ & $\mathrm{A} 2$ & $\mathrm{~A} 26$ & $\mathrm{~B} 15$ & Bw39 & & \\
\hline 18 Y.S. & $\mathrm{AC}$ & Aw24 & & Bw51 & B7 & & \\
\hline 19 H.T. & $\mathrm{AC}$ & $\mathrm{A} 2$ & Aw24 & B7 & B15 & & \\
\hline 20 M.I. & $\mathrm{AC}$ & $\mathrm{A} 2$ & A26 & B15 & Bw54 & Cw1 & Cw3 \\
\hline $21 \mathrm{~S} . \mathrm{N}$ & $\mathrm{AC}$ & A2 2 & & B15 & $\mathrm{B} 40$ & Cw3 & \\
\hline 22 H.M. & $\mathrm{AC}$ & Aw24 & Aw31 & Bw51 & Bw52 & Cw1 & \\
\hline 23 Т.Н. & $\mathrm{AC}$ & Aw31 & Aw33 & $\mathrm{B} 12$ & Bw35 & & \\
\hline 24 G.T. & $\mathrm{BC}$ & Aw24 & & Bw51 & Bw54 & Cw1 & \\
\hline 25 Y.Y. & $\mathrm{BC}$ & A2 & $A w 24$ & Bw35 & & & \\
\hline 26 K.M. & $\mathrm{BC}$ & Aw24 & A26 & B7 & & $\mathrm{Cw1}$ & \\
\hline 27 A.I. & $\mathrm{BC}$ & Aw24 & A11 & Bw52 & B40 & & \\
\hline 28 M.M. & $\mathrm{BC}$ & Aw24 & A26 & Bw52 & B40 & Cw3 & \\
\hline 29 I.A. & $\mathrm{BC}$ & $\mathrm{A} 2$ & Aw24 & $\mathrm{B} 40$ & & Cw3 & \\
\hline 30 M.O. & $\mathrm{BC}$ & $\mathrm{A} 2$ & Aw24 & $B w 52$ & B40 & & \\
\hline 31 K.O. & $\mathrm{BC}$ & A26 & & Bw54 & & Cw1 & \\
\hline 32 K.H. & $\mathrm{BC}$ & Aw24 & A26 & Bw51 & & Cw3 & \\
\hline
\end{tabular}


Table 4. Estimates of haplotype frequencies $(\mathrm{HFa})$ and linkage disequilibrium parameters (D) between $H L A$ and $C 2$

\begin{tabular}{rcrc}
\hline & HF & $\mathrm{D}$ & $\mathrm{t}$ \\
\hline$A w 24-C 2^{\mathrm{A}}$ & 0.0169 & -0.0013 & -0.16 \\
$A 26-C 2^{\mathrm{A}}$ & 0.0216 & 0.0122 & 1.83 \\
$B 15-C 2^{\mathrm{A}}$ & 0.0315 & 0.0254 & $3.48^{\mathrm{b}}$ \\
$B w 35-C 2^{\mathrm{A}}$ & 0.0116 & 0.0061 & 1.13 \\
$C w 3-C 2^{\mathrm{A}}$ & 0.0223 & 0.0062 & 0.83 \\
$A w 24-C 2^{B}$ & 0.0131 & 0.0061 & 1.33 \\
\hline
\end{tabular}

a Only the haplotypes exceeding 0.01 are given. b Significance level: $p<0.001$.

and type $B C$, respectively, following the nomenclature used by Alper (1976). The pequliarity of the $\mathrm{AC}$ type is that the acidic side variant bands are apparently stronger than the common bands. As to type $\mathrm{BC}$, the basic side variant bands have equal strength with the common bands.

The results of $\mathrm{C} 2$ typing of 292 unrelated samples are presented in Table 1. The allele frequencies for $C 2^{C}, C 2^{A}$, and $C 2^{B}$ were estimated to be $0.937,0.046$, and 0.017 , respectively. The distribution of $\mathrm{C} 2$ phenotypes was in good agreement with Hardy-Weinberg's equilibrium.

A total of 229 samples in the population material mentioned above were also typed for the HLA-A,B, and C specificities (Table 2). The C2 allele frequencies in this material agreed well with those in the whole material for $\mathrm{C} 2$ population study mentioned above. The results of HLA typing of 23 individuals of type C2 AC and 9 of type $\mathrm{C} 2 \mathrm{BC}$ are presented in Table 3 . Among the $\mathrm{C} 2 \mathrm{AC}$ individuals, eighteen had either B15 or Bw35, and two had both B15 and Bw35. By the t-test on the $\mathrm{C} 2 \mathrm{AC} / \mathrm{HLA}-\mathrm{A}, \mathrm{B}, \mathrm{C}$ data, the positive association of $C 2^{A}$ with $H L A-B 15$ was found to be statistically significant (Table 4). The linkage disequilibrium parameter of $C 2^{A} / B 15$ estimated from the present population data was: $\mathrm{D}=0.0254$ $(\mathrm{t}=3.48, \mathrm{p}<0.001)$. Nine $\mathrm{C} 2 \mathrm{BC}$ individuals were included, but no significant association between $C 2^{B}$ and HLA alleles was detected.

\section{DISCUSSION}

The common $\mathrm{C} 2$ type observed in the present study (Fig. 1c and d) is considered to be identical with C2 C reported by Alper (1976) or C2 1 by European authors (Meo et al., 1977; Olaisen et al., 1978; Dewald and Rittner, 1979). Likewise, the basic double-banded type observed in Japanese (Fig. 1a) corresponds to C2 BC reported by Alper, or $C 22-1$ by European authors. The frequency of $C 2^{B}$ in Japanese (0.017) is lower than those in the Europeans and the American Caucasians (0.025-0.04). 
The C2 "AC" type was first observed by Alper (1976) in the American Caucasians, and more recently, Pariser et al. (1978) described two rare acidic variants, $\mathrm{C} 2 \mathrm{~A} 1 \mathrm{C}$ and $\mathrm{C} 2 \mathrm{~A} 2 \mathrm{C}$. At present, it is not certain as to whether the type $\mathrm{AC}$ discovered in the present study (Fig. 1b) is identical with one of the Caucasian variants. In any case, it is noteworthy that in Japanese $C 2^{A}$ which is commoner than $C 2^{B}$ has a polymorphic frequency of 0.046 (Table 1). Because no "AC" types have been observed in the Europeans the occurrence of these types in the American Caucasians raises an interesting question on the origin of these variants. Alper (1976) reported the $C 2$ data in the Orientals $(n=43)$, in which three cases of type $\mathrm{C} 2 \mathrm{BC}$ were found, but none of type $\mathrm{C} 2 \mathrm{AC}$. However, the racial status of this "Oriental" sample was not given.

It is interesting that the significant positive association of $C 2^{A}$ with $H L A-B 15$ $(\mathrm{p}<0.001)$ was found in the present study (Table 4$)$. This finding is in contrast with the data reported in Caucasian populations, in which B15 is in linkage disequilibrium with $C 2^{B}\left(C 2^{2}\right)$ (Meo et al., 1976; Olaisen et al., 1978; Raum et al., 1979; Dewald and Rittner, 1979). Furthermore, two examples of C2 A1C in the American Caucasians were reported to show association with different HLA haplotypes, $A 2, B w 17$ and $A 3, B w 21$ (Raum et al., 1979). Therefore, the $C 2^{A}$ which is relatively common in Japanese population may have arisen by a mutation which occurred relatively recently in Japanese, or in some Mongoloid group. Further investigations of the distributions of $\mathrm{C} 2$ types and of C2/HLA association in other Mongoloid populations with known geographical origins are clearly needed.

Acknowledgements We wish to express our thanks to Dr. Eiichi Tokunaga, Director of the Japanese Red Cross Central Blood Center, Tokyo, for providing us with blood samples. Particular thanks are due to Dr. Yoichi Shibata, Blood Transfusion Service, Tokyo University Hospital, Tokyo, for valuable advices during this study. The excellent technical assistance of Miss Mitsuko Miyamoto is deeply appreciated.

\section{REFERENCES}

Agnello, V. 1978. Complement deficiency states. Medicine 57: 1-23.

Alper, C.A. 1976. Inherited structural polymorphism in human C2: Evidence for genetic linkage between $\mathrm{C} 2$ and Bf. $J$. Exp. Med. 144: 1111-1115.

Day, N.K., L'Esperance, P., Good, R.A., Michael, A.F., Hansen, J.A., Dupont, B., and Jersild, C. 1975. Hereditary C2 deficiency: Genetic studies and association with the HL-A system. $J$. Exp. Med. 141: 1464-1469.

Dewald, G. and Rittner, C. 1979. Polymorphism of the second component of human complement (C2). Vox Sang. 37: 47-54.

Fu, S.M., Kunkel, H.G., Brusman, H.P., Allen, F.H., Jr., and Fotino, M. 1974. Evidence for linkage between HL-A histocompatibility genes and those involved in the synthesis of the second component of complement. J. Exp. Med. 140:1108-1111.

Hobar, M.J. and Lachmann, P.J. 1976. Allotypes of complement components in man. Transplant. Rev. 32: 26-42.

Kerr, M.A. and Porter, R.R. 1978. The purification and properties of the second component of human complement. Biochem. J. 171: 99-107. 
Meo, T., Atkinson, J., Bernoco, M., Bernoco, D., and Ceppellini, R. 1976. Mapping of the HLA locus controlling $\mathrm{C} 2$ structural variants and linkage disequilibrium between alleles $\mathrm{C2}^{2}$ and Bw15. Eur. J. Immunol. 6: 916-919.

Meo, T., Atkinson, J.P., Bernoco, M., Bernoco, D., and Ceppellini, R. 1977. Structural heterogeneity of $\mathrm{C} 2$ complement protein and its genetic variants in man: $A$ new polymorphism of the HLA region. Proc. Natl. Acad. Sci. U.S.A. 74: 1672-1675.

Mittal, K.K., Hasegawa, T., Ting, A., Mickey, M.R., and Terasaki, P.I. 1972. Genetic variation in the HL-A system between Ainus, Japanese, and Caucasians. In: Histocompatibility Testing 1972. J. Dausset and J. Colombani, eds., Munksgaard, Copenhagen. pp. 187-195.

Nishioka, K., Tachibana, T., Okada, H., Mukojima, T., Torisu, M., Arata, M., Ohmi, K., and Kamiyama, Y. 1966. Experimental techniques on complement. In: Meneki no Seikagaku (Biochemistry in Immunity), Kyoritsu Publishing Co., Tokyo. pp. 199-214. (in Japanese)

Olaisen, B., Teisberg, P., Gedde-Dahl, T., Jr., and Thorsby, E. 1978. Genetic polymorphism of the second component of human complement (C2). Hum. Genet. 42: 301-305.

Pariser, K.M., Raum, D., Berkman, E.M., Alper, C.A. and Agnello, V. 1978. Evidence for a silent or null gene in hereditary C2 deficiency. J. Immunol. 121: 2580-2581.

Polley, M.J. and Müller-Eberhard, H.J. 1968. The second component of human complement: Its isolation, fragmentation by $\mathrm{C}^{\prime} 1$ esterase and incorporation into $\mathrm{C}^{\prime} 3$ convertase. $J$. Exp. Med. 128: 533-551.

Polley, M.J. 1971. Enhancement of hemolytic complement activity by treatment of human serum with iodine. J. Immunol. 107: 1493-1495.

Raum, D., Glass, D., Carpenter, C.B., Schur, P.H., and Alper, C.A. 1979. Mapping of the structural gene for the second component of complement with respect to the human major histocompatibility complex. Am. J. Hum. Genet. 31: 35-41. 